\title{
Climate Change Indication and Projection Over Bale Highlands, Southeastern Ethiopia
}

Legese $\mathbf{W}^{*}$

Madda Walabu University, Environmental Science Department, Bale Robe, Ethiopia

\begin{abstract}
Global climate has been changing and in fact expected to change in more shocking degree. Therefore, the objective of the current study is to understand climate change signal, downscale climate change scenario for Bale highlands using CORDEX_GCM Models and identify the occurrence of climate change signal in Bale highlands. This study was aimed to make in-depth statistical analysis on past and future climatic trend, rainfall patterns and temperature trends as well as changes for various time scales over Bale highlands. Climate data recorded at meteorological station located in Bale highlands were obtained from National Meteorological Agency Bale Robe Meteorological Branch Directorate while model output of the two RCP4.5 and RCP8.5 scenarios was downloaded from CORDEX Africa Group Data library. Various statistical techniques were employed on rainfall and temperature to analyze and interpret the past and future climatic condition for rainy season over the Bale highlands. The results revealed that the climate change signal was appear over Bale Highlands. The change in temperature over Bale highlands under RCP4.5 and RCP8.5 emission scenarios shown as an increase for the period of near century, mid-century and end century. Changes of temperature under RCP8.5 was higher than the change of temperature in RCP4.5 scenario for all three periods (near, mid and end Century). Rainfall change for near, mid and end centuries under RCPs scenarios were variable.
\end{abstract}

Keywords: Climate change signal; Cordex Africa; Bale highlands; Rainfall; Temperature

\section{Introduction}

Global climate has been changing and in fact expected to change in more alarming rate. The average global surface temperature warmed by about $0.8^{\circ} \mathrm{C}$ in the past century and $0.6^{\circ} \mathrm{C}$ in the past three decades [1], mainly due to human activities [2]. Global Climate Models indicated warming projection for all seasons in all regions of Ethiopia. Using the medium high SRES A2 emissions scenario, Conway and Schipper [3] reported an average increase in temperature across Ethiopia by the $2020 \mathrm{~s}$ and 2050 s with a range of $0.7-2.3^{\circ} \mathrm{C}$, and $1.4-2.9^{\circ} \mathrm{C}$, respectively [4].

In 2007, the Intergovernmental Panel on Climate Change [5] published its Fourth Assessment Report (AR4) assembling the most recent scientific research results and information regarding climate change. According to the AR4, it is very likely that most parts of continent of Africa will warm during this century and that throughout Africa and in all seasons. The warming will be larger than the global annual mean values. Based on the multi-model-dataset (MMD) of 21 global models and on the A1B-scenario, the projections for East Africa indicate that the median near-surface temperature in the 2080 to 2099 period will increase by $3^{\circ} \mathrm{C}$ to $4^{\circ} \mathrm{C}$ as compared to the $1980-1999$ periods. It is important to note that this increment is about 1.5 times the projected global mean response [5].

Projected maximum and minimum temperatures over equatorial eastern Africa show a significant increase in the number of days warmer than $2^{\circ} \mathrm{C}$ above the 1981-2000 average by the middle and end of the $21^{\text {st }}$ century under the SRES A1B and A2 scenarios [6]. Temperature projections from the most recent IPCC report using Representative Concentration Pathways indicate that considerable warming for the region of east Africa, consistent with previous work, with the degree of warming greatest for higher greenhouse gas emissions pathways [4].

The authors further stated that "multiple sources of evidence converge on a post-1997 tendency towards lower rainfall, especially during the Belg (March- May) season. This finding appears to be present for many parts of eastern Africa."
From the IPCC Fourth Assessment Report [5] and Tadege [7] there is a general consensus on the rise of the temperature. Sayed [8] has shown that the change in rainfall over the Blue Nile basin would be between +2 and $+11 \%$ for 2030 , while rainfall over the White Nile basin would increase between 1 and $10 \%$ for the same year.

Projections of future change from different climate models can result in large ranges of future change. There is a change in annual temperature and annual precipitation relative to 1986-2005 under different greenhouse gas emissions pathways for East Africa [4]. Under RCP 8.5 , the average warming across all models shows temperature increment of approximately $4^{\circ} \mathrm{C}$ by the end of the century. When the range of projections from individual models is examined, some showed temperature increment approaching and exceeding $6^{\circ} \mathrm{C}$ by the same period. Under ambitious global greenhouse gas emission reductions (represented by RCP2.6) temperatures are expected to increase by approximately $1^{\circ} \mathrm{C}$ by the end of the century, however, even under this ambitious scenario increases in mean annual temperature above current conditions still approach $2^{\circ} \mathrm{C}[4]$.

Regional differences in warming are modest, with warming associated with a greater frequency of heat waves and increases in evaporation leading to moisture deficits. Elshamy et al. [9] show a temperature increase over the upper Blue Nile of between $2^{\circ} \mathrm{C}$ and $5^{\circ} \mathrm{C}$ at the end of the $21^{\text {st }}$ Century under the $\mathrm{A} 1 \mathrm{~B}$ scenario compared to the period 1961-1990.

*Corresponding author: Legese W, Madda Walabu University, Environmental Science Department, Bale Robe, Ethiopia, Tel: +251-913121959; E-mail: wogmet@gmail.com

Received July 22, 2017; Accepted October 18, 2017; Published October 25, 2017

Citation: Legese W (2017) Climate Change Indication and Projection Over Bale Highlands, Southeastern Ethiopia. J Climatol Weather Forecasting 5: 212. doi:10.4172/2332-2594.1000212

Copyright: ( 2017 Legese W. This is an open-access article distributed under the terms of the Creative Commons Attribution License, which permits unrestricted use, distribution, and reproduction in any medium, provided the original author and source are credited. 
For Ethiopia, even the projected temperature change under the most ambitious emissions scenarios will have significant impacts on agriculture, extreme events and the livelihoods of many [4]. So far there is no significant study to understand climate change scenario for Bale Highlands. Therefore, the objective of the current study was to understand to climate change signal, downscale climate change scenario for Bale highlands using CORDEX_GCM Models and identify the occurrence of climate change signal in Bale highlands.

\section{Materials and Methods}

\section{Background of the study area}

Highlands of Bale is located between $6.45^{\circ} \mathrm{N}$ to $7.45^{\circ} \mathrm{N}$ and $39.47^{\circ} \mathrm{E}$ to $40.77^{\circ} \mathrm{E}$ in the southern parts of Oromia Regional State of Ethiopia. The elevation of the area ranges from 1500 to 3500 meter above sea level [10]. The study area covers 9 Districts of the Zone, namely; Agarfa, Berebere, Dinsho, Gasera, Ginir, Goba, Gololcha, Goro and Sinana, which covers $13,291 \mathrm{~km}^{2}$. The study area is bordered in the south by Mena, in the west by West Arsi Zone, in the north by Arsi Zone, in the northeast by Legehida district, in the southeast by Guradamole district of Bale zone and in the east by Sewena district. The highest point in Bale Highland is Mount Tuludimtu (4377 m) and Batu Mount (4307 m). Based on the topography Bale Zone is divided into Dega (Highland), Waine Dega (mid lands), and Kola (low lands). Accordingly, there are two cropping seasons in the area: Ganna (March to June) and Bona (July to December) seasons. In the study area, Barley and Wheat are highly produced [11]. Most of these districts are characterized by bimodal rainfall types. The average rainfall is about $590 \mathrm{~mm}$ in the Ganna and $560 \mathrm{~mm}$ in Bona season. Various studies indicate that the study area is dense or populous because the region is highly fertile and suitable for agricultural activities [12]. The current study is mainly focused on the Highlands parts of Bale Zone (Figure 1) [13].

\section{Data used and method of analysis}

Observed meteorological data (Data sources): All historical meteorological data were collected from National Meteorological Agency (NMA) of Ethiopia Bale Robe Meteorological Branch
Directorate. These datasets include daily rainfall, maximum temperature, and minimum temperature. Within Bale Highlands, National Meteorological Agency has 12 meteorological stations. However, only 5 stations have rainfall, maximum and minimum temperature. Whereas, 7 meteorological stations have only recorded rainfall data, which are $4^{\text {th }}$ level meteorological stations. Model output of the two emission scenarios were downloaded from CORDEX Africa Group [14].

Global climate model (GCM) data: For this study, downscaled daily climate output from CORDEX- Global Climate Model, which is for the new RCPs scenarios were used. The new RCP scenarios were also used for the RCP4.5 and RCP8.5. The assumptions of Both RCP4.5 and RCP8.5 for future were the released of greenhouse gas, pollutants, socio-economic change, technological change, energy, land use and other driving forces [15]. The CORDEX- GCM provides daily meteorological forcing for the period 1951-2100.

RCP4.5: Under RCP4.5 scenario, GHG emissions peak around mid-century at around 50\% higher than 2000 levels decline rapidly over 30 years, and then stabilize at half of 2000 levels. Nuclear power and renewable energy sources play a greater role. Significantly, cropping and grassland area declines, while reforestation increases the area of natural vegetation.RCP4.5was developed by the GCAM modeling team at the Pacific Northwest National Laboratory's Joint Global Change Research Institute (JGCRI) in the United States. RCP4.5 scenario has a policy or restriction on the emission of GHG and distribution of industry. It is a stabilization scenario in which total radiative forcing is stabilized shortly after 2100 , without overshooting the long-run radiative forcing target level [16].This scenario was an intermediate stabilization scenario leading to $4.5 \mathrm{~W} / \mathrm{m}^{2}[16]$.

RCP8.5: Under RCP8.5 scenario, GHG emissions continue to increase rapidly through the early and mid-parts of the century and then stabilized at just under $30 \mathrm{Gt}$ of carbon compared to around $8 \mathrm{Gt}$ in 2000. This scenario is highly energy intensive with total consumption continuing to grow throughout the century reaching well over 3 times current levels. Land use continues current trends with crop and grass areas increasing and forest area decreasing.

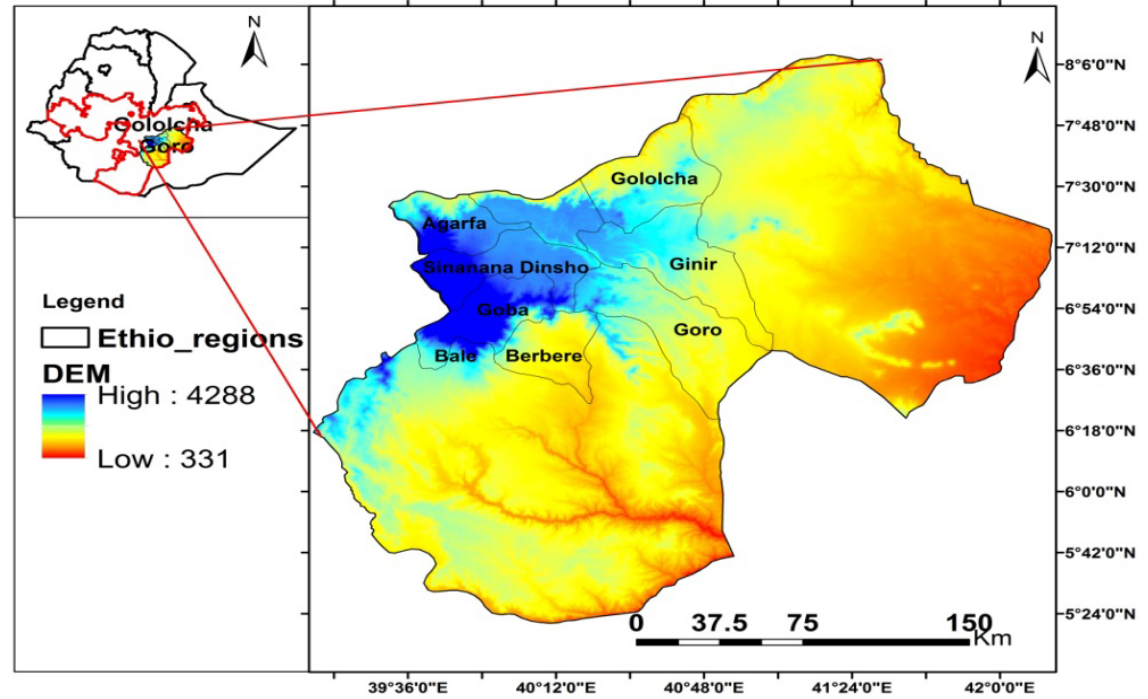

Figure 1: Map of the study area (Bale highlands). 
Citation: Legese W (2017) Climate Change Indication and Projection Over Bale Highlands, Southeastern Ethiopia. J Climatol Weather Forecasting 5: 212. doi:10.4172/2332-2594.1000212

Page 3 of 10

The RCPs have been selecting from existing literature to span the full range of possible trajectories for future greenhouse concentration. RCP8.5 scenario has no any policy or restriction to minimize the emission of GHG at the end of $21^{\text {st }}$ century. RCP 8.5 was developed using the MESSAGE model and the IIASA Integrated Assessment Framework by the International Institute for Applied Systems Analysis (IIASA), Austria. This RCP is characterized by increasing greenhouse gas emissions over time, representative of scenarios in the literature that lead to high greenhouse gas concentration levels [17]. This scenario was a very high emission scenario leading to $8.5 \mathrm{~W} / \mathrm{m}^{2}[17,18]$.

\section{Result and Discussion}

This chapter covers the validation of CORDEX-GCM using OBSERVED data of climate variables, as well as discuss the trends of Maximum and Minimum temperature, rainfall of baseline periods [4]. Climate change signal results for near, mid and end century over Bale Highlands are discussed thoroughly.

\section{Validation of GCM with observed (Temperature and Rainfall)}

The downscaled simulated maximum and minimum temperatures over Bale highlands had a good agreement with the observed results than rainfall (Table 1).Though downscaled values of rainfall showed a worse agreement as compared to the maximum temperature and minimum temperatures in Bale Highlands. Validation was done based on 20 years simulation from 1986-2005 [4]. Validation statistics for maximum and minimum temperatures and rainfall in Bale highlands are shown in Table 1.

\section{Maximum temperature}

The downscaled average maximum temperature reveals that good quality relations with the observed temperature for the baseline period (Figure 2a).

\section{Minimum temperature}

Like that of the maximum temperature the downscaled minimum temperature also shows a reasonably good agreement with the observed minimum temperature for Bale highlands (Figure 2b).

\section{Rainfall}

The downscaled average of rainfall expresses good quality relations with the Observed rainfall in both Belg(MAM) and Kiremt(JJAS) seasons for baseline period. Belg downscaled average Rainfall $97.8 \%$ was match to observed rainfall over Bale Highland in baseline periods (1986-2005) (Figure 3a, Table 2).In the same way, Kiremt season downscaled average rainfall was $95.2 \%$ match to observed rainfall over Bale Highlands (Figure 3b, Table 3).

Variability of rainfall can be expressed by statistical parameters such as mean, standard deviation and the coefficient of variability (CV). According to Hare (1983), CV is used to classify the degree of variability of rainfall events as less, moderate and high. When $\mathrm{CV}<20 \%$ it is less variable, $\mathrm{CV}$ from $20 \%$ to $30 \%$ is moderately variable, and $\mathrm{CV}>30 \%$ is highly variable. Areas with $\mathrm{CV}>30 \%$ are said to be vulnerable to drought.

The observed CV for Belg season was moderate variable i.e. $25.9 \%$ and the downscaled was highly variable i.e. $31.0 \%$. The high value of $\mathrm{CV}$ shows that there is a vulnerable of the season to climate change.

\begin{tabular}{|c|c|c|c|c|}
\hline Parameter & $\begin{array}{c}\text { Maximum } \\
\text { Temperature }\end{array}$ & $\begin{array}{c}\text { Minimum } \\
\text { Temperature }\end{array}$ & \multicolumn{2}{|c|}{ Rainfall } \\
\hline $\mathbf{R}^{2}$ & 0.53 & 0.58 & FMAM & JJAS \\
\cline { 3 - 5 } & & & 0.13 & 0.16 \\
\hline
\end{tabular}

Table 1: $R^{2}$ value between Simulated and observed data for baseline period.

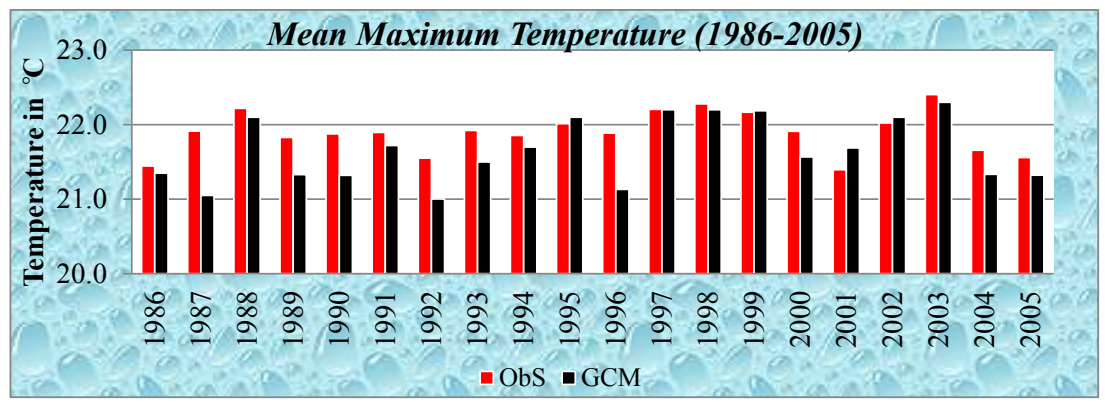

Figure 2a: Downscaled and observed Maximum temperature (1986-2005).

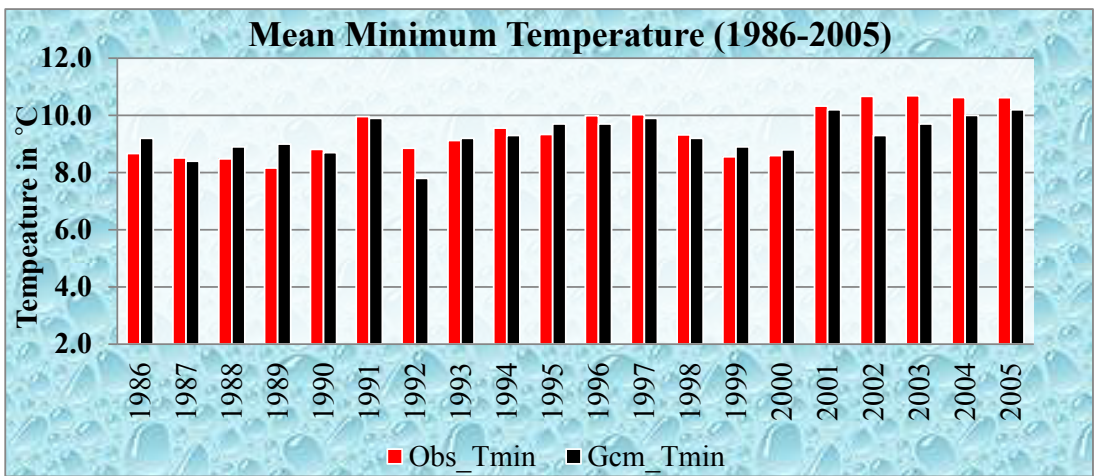

Figure 2b: Downscaled and observed temperature (1986-2005). 


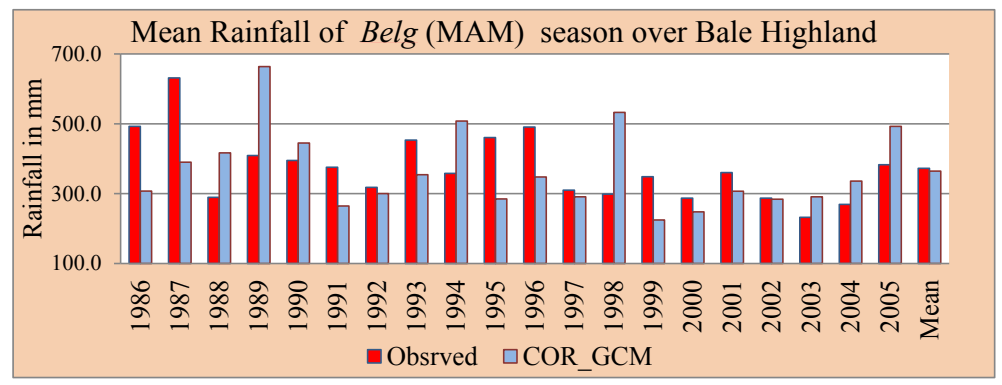

Figure 3a: Downscaled and observed mean Rainfall during Belg (1986-2005).

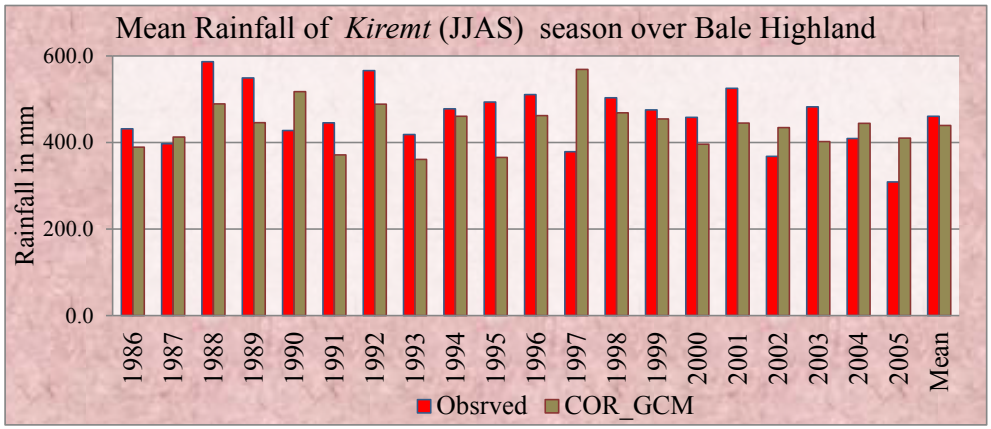

Figure 3b: Downscaled and observed mean Rainfall during Kiremt (1986-2005).

\begin{tabular}{|c|c|c|}
\hline Statistical Parameters & Observed (1986 to 2005) & GCM (1986 to 2005) \\
\hline Mean $(\bar{x})$ & 372.6 & 364.5 \\
\hline Variance (Var) & 9309.3 & 12808.4 \\
\hline Standard Deviation(SD) & 96.5 & 113.2 \\
\hline Coefficient of variation CV (\%) & 25.9 & 31.0 \\
\hline
\end{tabular}

Table 2: Rainfall variability and Coefficient of variation classes for Belg season.

As a result of Figure $3 b$, the observed and estimated value of rainfall in Kiremt season over Bale Highlands matches to each other except for 1997 years. Especially the mean of the observed and model output was exactly contest. The CV for Kiremt season both observed and downscaled shows less variability's. That is 14.9 and $11.8 \%$, respectively. For threshold value of Kiremt season (Table 3).

\section{Maximum and minimum temperature}

The trends of minimum and maximum temperature in Kiremt and Belg seasons under near century (2011 to 2040) in RCP4.5 scenario will increase (Figure $4 \mathrm{a}$ and $4 \mathrm{~b}$ ) respectively. The trends of minimum temperature will increase than maximum temperature under RCP8.5 in near century for Kiremt and Belg seasons. The tendencies of minimum and maximum temperature in Kiremt and Belg seasons beneath near century (2011 to 2040) in RCP8.5 scenario will increase (Figure 4c and $4 \mathrm{~d})$ respectively. The trends of minimum temperature will increase as compare to maximum temperature under RCP8.5 in near century for Kiremt and Belg seasons over Bale Highlands.

The maximum temperature change from reference (1986 to 2005, IPCC, 2014) in near century for Kiremt and Belg seasons under RCP4.5 scenario for Kiremt and Belg seasons will be 1.5 and 1.2 in ${ }^{\circ} \mathrm{C}$, respectively (Figure $5 \mathrm{a}$ ). The maximum temperature change underRCP8.5 scenario will be 3.2 and 3.7 in ${ }^{\circ} \mathrm{C}$, respectively (Figure

\begin{tabular}{|c|c|c|}
\hline Statically Parameters & Observed (1986 to 2005) & GCM (1986 to 2005) \\
\hline Mean $(\bar{x})$ & 460.7 & 439.4 \\
\hline Variance (Var) & 4967.6 & 2819.7 \\
\hline Standard Deviation(SD) & 68.7 & 51.8 \\
\hline Coefficient of Variation CV (\%) & 14.9 & 11.8 \\
\hline
\end{tabular}

Table 3: Rainfall variability and Coefficient of variation classes for Kiremt season.

$5 b)$. The maximum temperature change in near term will be high in RCP8.5 than RCP4.5. Similarly, minimum temperature change from the base year in Kiremt and Belg seasons under RCP4.5 and RCP8.5 scenarios will be 1.2, 1.2, 2.3 and 2.4 in ${ }^{\circ} \mathrm{C}$, respectively. Figure $5 \mathrm{a}$ and $5 \mathrm{~b}$ are shown as Change in Maximum and Minimum Temperature at the end of near century over the Bale highlands.

The trends of both maximum and minimum temperature showed in (Figure 6a and 6b), will increase in Kiremt and Belg seasons for intermediate future (2041-2070) under RCP4.5 scenario respectively. The trends of minimum temperature will increase than maximum temperature under RCP4.5 in mid-century for Kiremt and Belg seasons.

The tendencies of minimum temperature in Kiremt and Belg seasons beneath intermediate century (2041 to 2070) in RCP8.5 scenario will increase (Figure $6 \mathrm{c}$ ) and the maximum temperature under RCP8.5 scenario will increases in Kiremt and Belg seasons (Figure $6 \mathrm{~d}$ ). The trends of minimum temperature will increase as compare to maximum temperature under RCP8.5 in mid-century for Kiremt and Belg seasons over Bale Highlands.

The maximum and minimum temperature change at end mid-century (2041 to 2070) from reference period (1986-2005) in RCP4.5 scenario for Kiremt and Belg seasons will be 2.4, 2.6, 2.7 and 2.7 in ${ }^{\circ} \mathrm{C}$, respectively (Figure $7 \mathrm{a}$ ). Similarly, the maximum and 


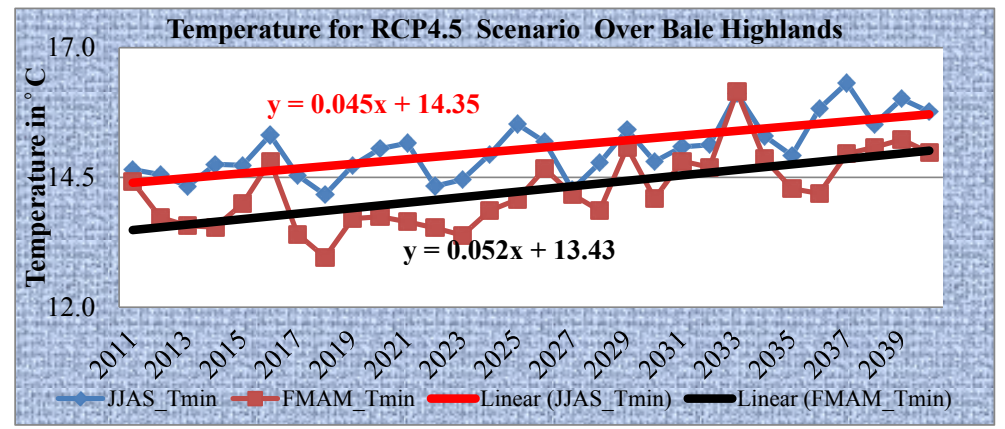

Figure 4a: Trend of minimum Temperature for RCP4.5 during near future over Bale highlands.

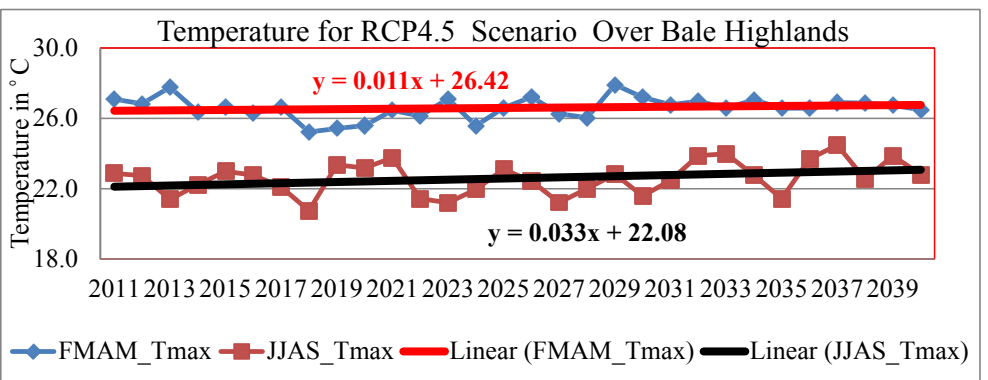

Figure 4b: Trend of Maximum Temperature for RCP4.5 during near future over Bale highlands.

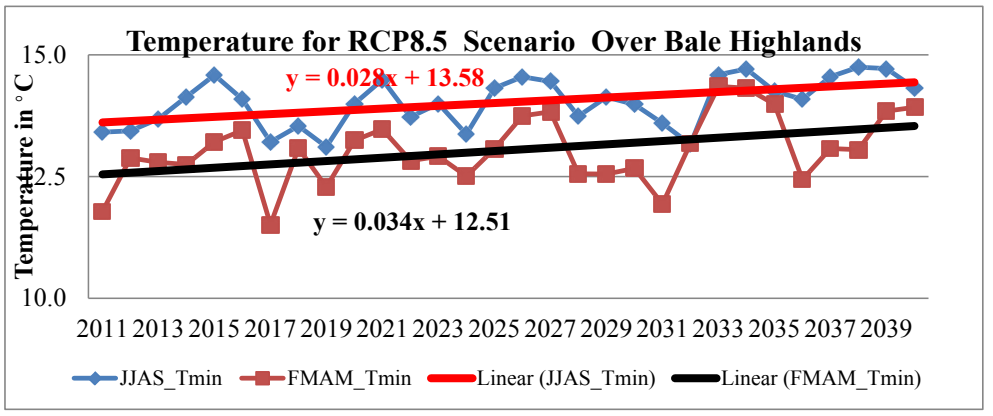

Figure 4c: Trend of minimum Temperature for RCP8.5 during near future over Bale highlands.

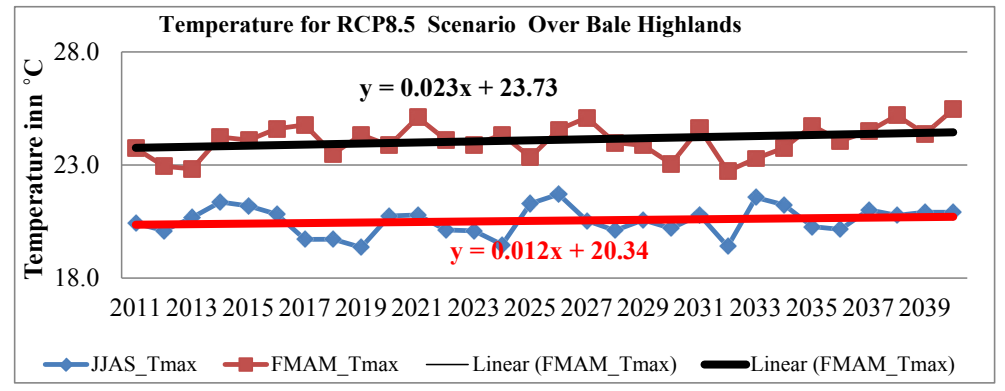

Figure 4d: Trend of Maximum Temperature for RCP8.5 during near future over Bale highlands.

minimum temperature change at end mid-century (2041 to 2070) under RCP8.5 scenario for kiremt and belg seasons will be 4.0, 3.0, 4.6, and 3.2 in ${ }^{\circ} \mathrm{C}$, respectively (Figure $7 \mathrm{~b}$ ). Generally, there was a progressive increment in both maximum and minimum temperature change for intermediate future periods over Bale highland. The change in maximum temperature was high in RCP8.5 scenario as compared to RCP4.5 in the study area (Bale Highlands). Figure $6 \mathrm{a}$ and $6 \mathrm{~b}$ are shown as Change in Maximum and Minimum Temperature at the end of mid-future over the Bale highlands. 


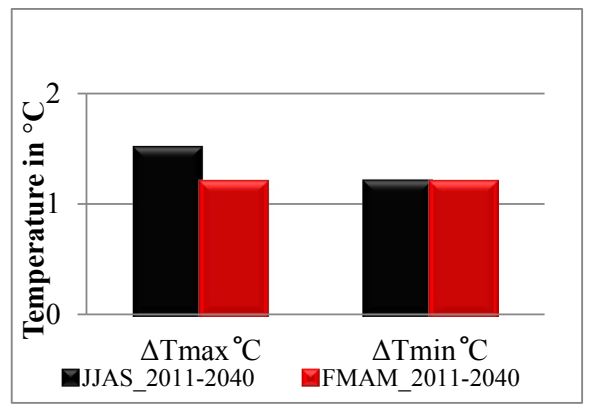

Figure 5a: Change of Temperature for RCP4.5.

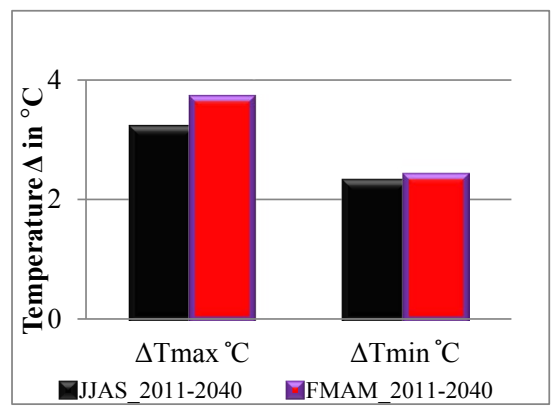

Figure 5b: Change of Temperature for RCP8.5.

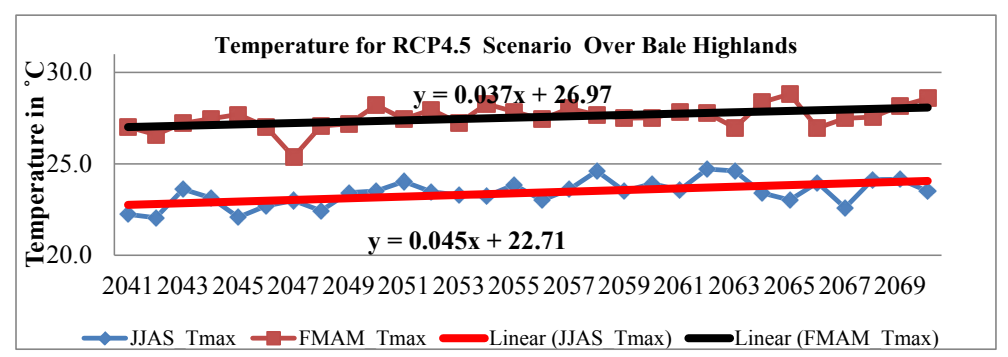

Figure 6a: Trend of maximum Temperature for RCP4.5 during near future over Bale highlands.

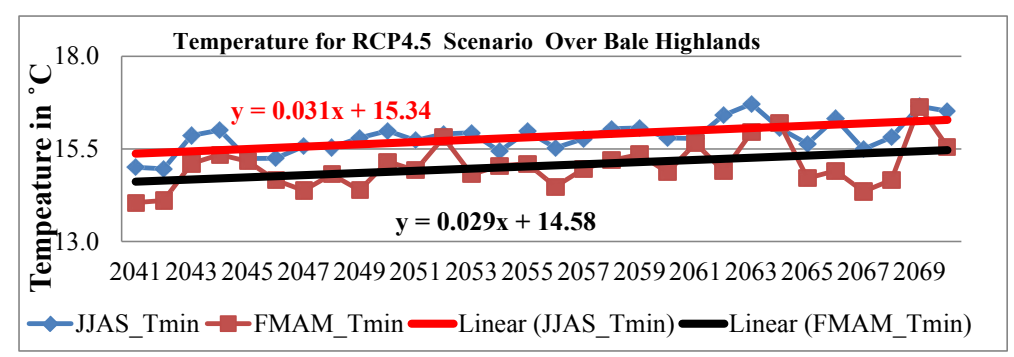

Figure 6b: Trend of minimum Temperature for RCP4.5 during near future over Bale highlands.

The trends of minimum temperature in Kiremt and Belg seasons at the end of $21^{\text {st }}$ century (2071 to 2100) in RCP4.5 scenario will increase (Figure $8 \mathrm{a}$ ) and the maximum temperature under RCP4.5 scenario will increases in Kiremt than Belg seasons (Figure 8b).

The propensity of minimum temperature in Kiremt and Belg seasons at the end of $21^{\text {st }}$ century (2070 to 2100 ) in RCP8.5 scenario will increase (Figure 8c) and the maximum temperature under RCP8.5 scenario will increases in Kiremt and Belg seasons (Figure 8d). The trends of minimum temperature will increase as compare to maximum temperature under RCP8.5 at the end of $21^{\text {st }}$ century for Kiremt and Belg seasons over Bale Highlands.

The maximum and minimum temperature change at end of $21^{\text {st }}$ century (2071 to 2100) from reference period (1986-2005) in RCP4.5 scenario for kiremt and belg seasons will be 4.5, 3.5, 4.6 and 3.9 in ${ }^{\circ} \mathrm{C}$, respectively (Figure 9a). Similarly, the maximum and minimum temperature change at end of $21^{\text {st }}$ century (2071 to 2100 ) under RCP8.5 


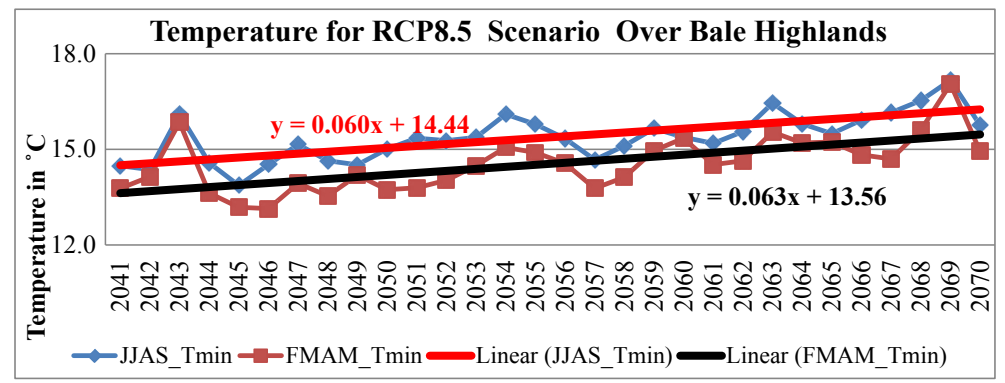

Figure 6c: Trend of Minimum Temperature for RCP8.5 during near future over Bale highlands.

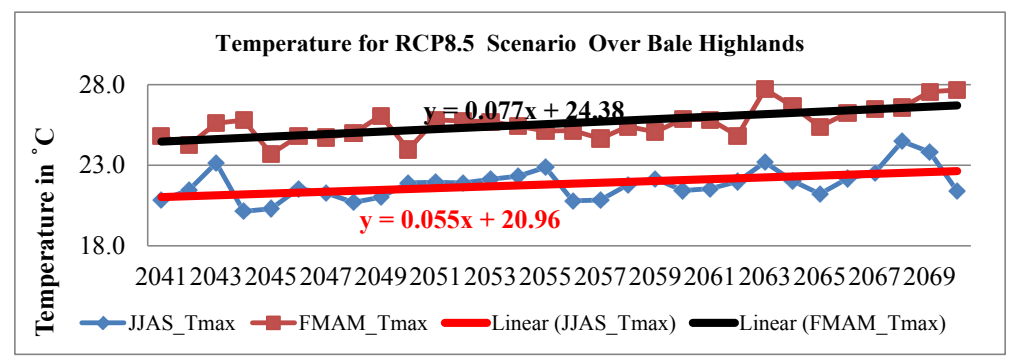

Figure 6d: Trend of maximum Temperature for RCP8.5 during near future over Bale highlands.

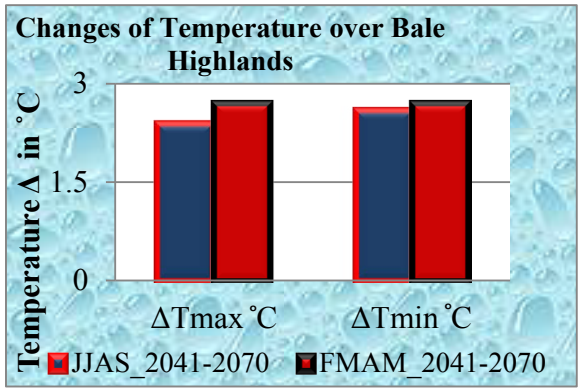

Figure 7a: Change of Temperature for RCP4.5.

scenario for kiremt and belg seasons will be 4.7, 3.8, 5.3 and 4.2 in ${ }^{\circ} \mathrm{C}$, respectively (Figure 9b). Generally, there was a progressive increment in both maximum and minimum temperature change at the end of $21^{\text {st }}$ century over Bale highlands. The change in both minimum and maximum temperature was high in RCP8.5 scenario as compared to RCP4.5 in the study area (Bale Highlands). Figure $9 a$ and $9 b$ are shown as Change in Maximum and Minimum Temperature at the end of endcentury over the Bale highlands.

As it was presented in Table 4 the maximum temperature change for the period between intermediate century (2041 to 2070) and near century (2011 to 2040) will be increased by $0.8^{\circ} \mathrm{C}$ and the minimum temperature change will be increased by $0.7^{\circ} \mathrm{C}$ in Kiremt season and in Belg season maximum and minimum temperature will be increased by 0.9 and $0.8^{\circ} \mathrm{C}$, respectively under RCP 4.5 scenario. Similarly, the maximum temperature change between end of $21^{\text {st }}$ century (2071 to 2100 ) and intermediate century (2041 to 2070) will be $0.3^{\circ} \mathrm{C}$ and the minimum temperature change will be $0.3^{\circ} \mathrm{C}$ Kiremt season. In Belg season maximum and minimum temperature will be change by 0.4 and $0.5^{\circ} \mathrm{C}$ under RCP4.5 scenario. The maximum and minimum temperature change for the period between intermediate century (2041

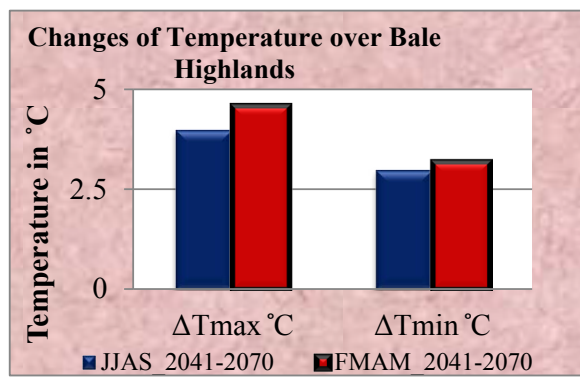

Figure 7b: Change of Temperature for RCP8.5.

\begin{tabular}{|c|c|c|c|c|}
\hline $\begin{array}{c}\text { RCPs } \\
\text { Scenarios }\end{array}$ & Seasons & Elements & $\begin{array}{l}\text { Between mid- } \\
\text { century ( } 2041 \text { to } \\
2070 \text { and Near } \\
\text { term century ( } \\
2011 \text { to } 2040 \text { ) }\end{array}$ & $\begin{array}{c}\text { Between end } \\
\text { century (2071 to } \\
2100) \text { and mid- } \\
\text { century }(2041 \text { to } \\
2070)\end{array}$ \\
\hline \multirow{2}{*}{ RCP4.5 } & \multirow{2}{*}{ JJAS } & $\Delta T_{-}$max in ${ }^{\circ} \mathrm{C}$ & 0.8 & 0.3 \\
\hline & & $\Delta T_{-} \min$ in ${ }^{\circ} \mathrm{C}$ & 0.7 & 0.3 \\
\hline \multirow{4}{*}{ RCP8.5 } & \multirow{2}{*}{ FMAM } & $\Delta \mathrm{T} \_$max in ${ }^{\circ} \mathrm{C}$ & 0.9 & 0.4 \\
\hline & & $\Delta T_{-} \min$ in ${ }^{\circ} \mathrm{C}$ & 0.8 & 0.5 \\
\hline & \multirow{2}{*}{ JJAS } & $\Delta T_{-}$max in ${ }^{\circ} \mathrm{C}$ & 1.3 & 2.2 \\
\hline & & $\Delta T_{-} \min$ in ${ }^{\circ} \mathrm{C}$ & 1.4 & 1.9 \\
\hline & \multirow{2}{*}{ FMAM } & $\Delta T \_\max$ in ${ }^{\circ} \mathrm{C}$ & 1.5 & 1.9 \\
\hline & & $\Delta T \_$min in ${ }^{\circ} \mathrm{C}$ & 1.5 & 2.2 \\
\hline
\end{tabular}

Table 4: Change of temperature between each period of century.

to 2070) and near century (2011 to 2040) will be increased by 1.3 and $1.3^{\circ} \mathrm{C}$ Kiremt season and in Belg season maximum and minimum temperature will be increased by 1.5 and $1.5^{\circ} \mathrm{C}$, respectively under RCP8.5 scenario. Similarly, the maximum and minimum temperature change between end of $21^{\text {st }}$ century (2071 to 2100) and intermediate century (2041 to 2070 ) will be 2.2 and $1.9^{\circ} \mathrm{C}$ in Kiremt season. In 


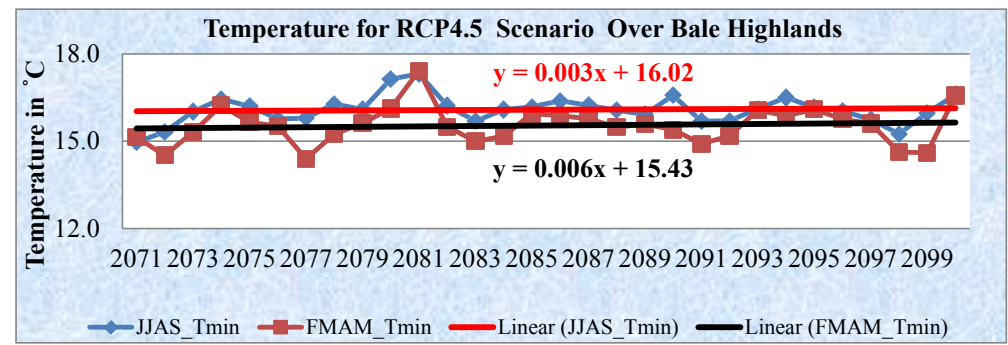

Figure 8a: Trend of Minimum Temperature for RCP4.5 during end of century over Bale highlands.

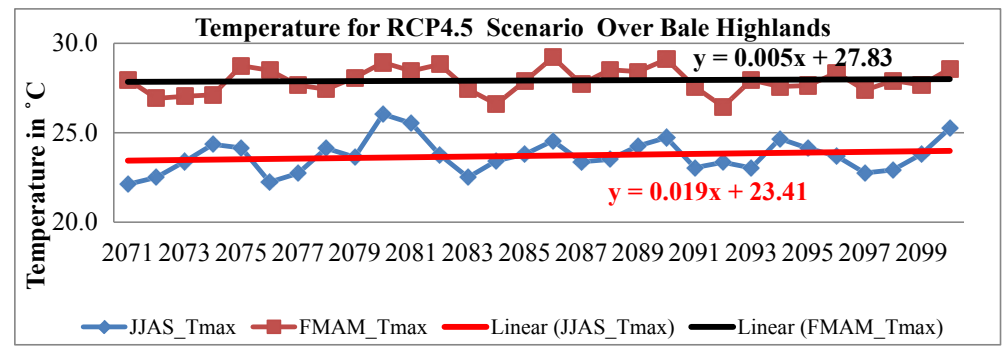

Figure 8b: Trend of Maximum Temperature for RCP4.5 at end of century over Bale highlands.

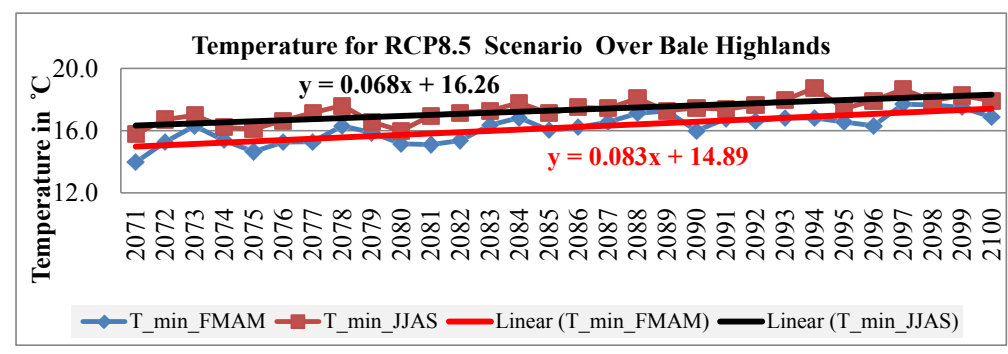

Figure 8c: Trend of Minimum Temperature for RCP8.5 at end of century over Bale highlands.

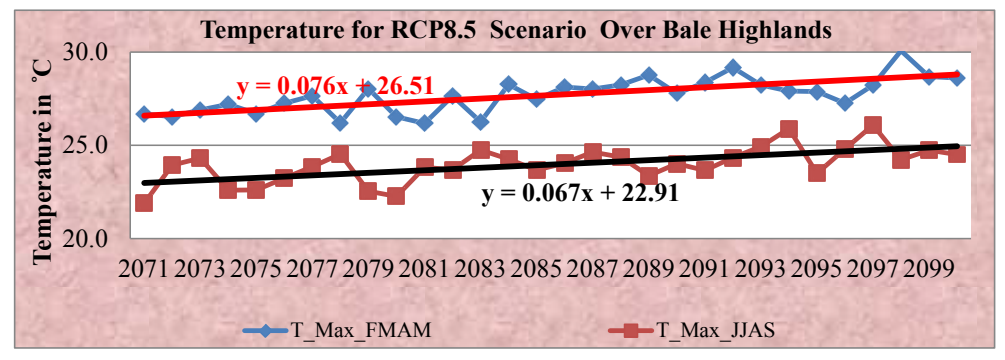

Figure 8d: Trend of Maximum Temperature for RCP8.5 at end of century over Bale highlands.

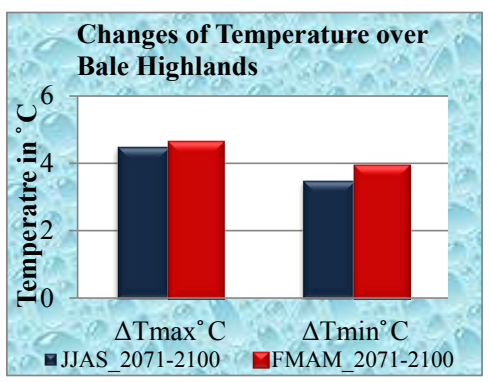

Figure 9a: Change of Temperature for RCP4.5.

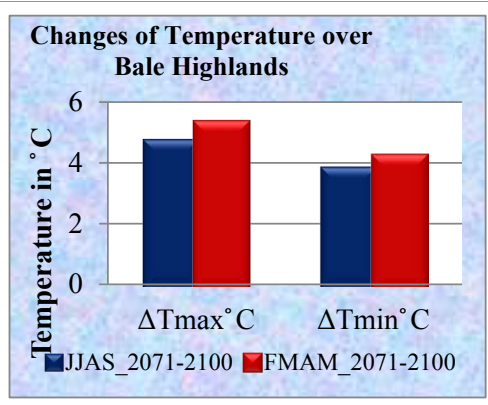

Figure 9b: Change of Temperature for RCP8.5. 
Citation: Legese W (2017) Climate Change Indication and Projection Over Bale Highlands, Southeastern Ethiopia. J Climatol Weather Forecasting 5: 212. doi:10.4172/2332-2594.1000212

Page 9 of 10

Belg season maximum and minimum temperature will be change by 1.9 and $2.2^{\circ} \mathrm{C}$ under RCP8.5 scenario. Both maximum and minimum temperature was higher in RCP8.5 as compare to RCP4.5 scenario.

\section{Rainfall}

The percentage change of rainfall: The subtraction of 2011-2040, 2041 -2070 and 2071-2100 mean from 1986 - 2005 mean and divide the result by mean of the baseline precipitation (1986-2005) and finally multiply the result by 100 .

\section{Percentage change of precipitation $=(\text { difference } / \text { base })^{*} 100$}

Where:

Difference $=$ the subtraction of 2011-2040, 2041-2070 and 20712100 mean from (1986-2005 mean), Base year= baseline precipitation (1986-2005: IPCC, 2014).

Belg (small rainy season): The seasonal change in rainfall for small rainy season will be increased by $7.7 \%$ and $9.1 \%$ under RCP 4.5 and RCP8.5 scenarios in the near century. The change in rainfall for Belg season will higher in RCP8.5 scenario in near century (Figure 10a). Belg season rainfall change in the mid-century will be increased by $3.8 \%$ and decreased by $6.5 \%$ under RCP 4.5 and RCP 8.5 scenarios. The change in rainfall for Belg season will highly decrease under RCP8.5 scenario in intermediate century (Figure 10b). The Belg

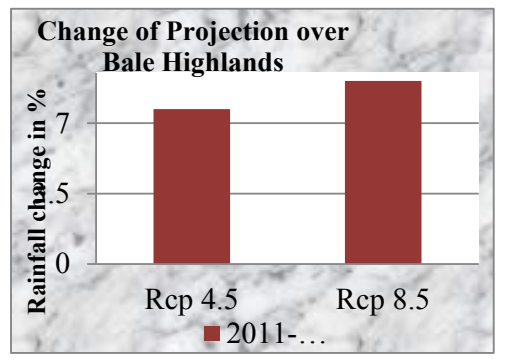

Figure 10a: Change of rainfall at end of near century.

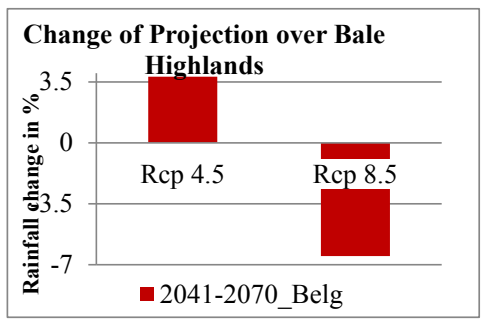

Figure 10b: Change of rainfall at end of mid-century

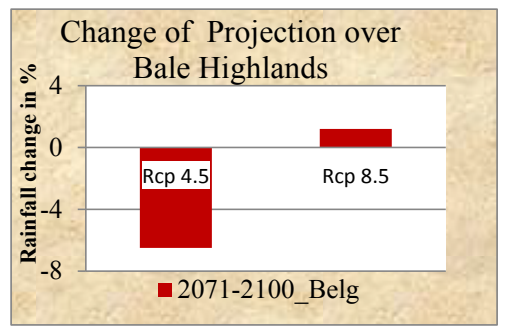

Figure 10c: Change of rainfall at end of century. seasonal rainfall change at the end of $21^{\text {st }}$ century will be decreased by $6.5 \%$ and increased by $1.2 \%$ under RCP 4.5 and RCP 8.5 scenarios, respectively. The change in rainfall for Belg season at the end of $21^{\text {st }}$ century will highly decrease under RCP4.5 scenario and increased under RCP8.5 scenario (Figure 10c).

Kiremt (Main rainy season): The seasonal rainfall change in kiremt season will be increased by 11.2 and $6.7 \%$ under RCP 4.5 and RCP8.5 scenarios in the near century over Bale Highlands, respectively. The change in rainfall was higher in RCP4.5 scenario than RCP8.5 scenario (Figure 10d). Kiremt season rainfall change in the mid-century will be increased by $12.1 \%$ and decreased by $11.7 \%$ under RCP4.5 and RCP8.5 scenarios, respectively. The change in rainfall for Kiremt season will highly decrease under RCP8.5 scenario in intermediate century (Figure 10e). The Kiremt seasonal rainfall change at the end of $21^{\text {st }}$ century will be increased by $2.9 \%$ and decreased by $0.64 \%$ under RCP 4.5 and RCP8.5 scenarios, respectively. The change in rainfall for Kiremt season at the end of $21^{\text {st }}$ century will highly increase under RCP4.5 scenario and decreased under RCP8.5 scenario (Figure 10f).

Figure 10a-10c are shown as Change rainfall at the end of endcentury, mid-century and end of end century over the Bale highlands in Belg season. Figure 10d-10f are shown as Change rainfall at the end of end-century, mid-century and end of end century over the Bale highlands in Kiremt season.

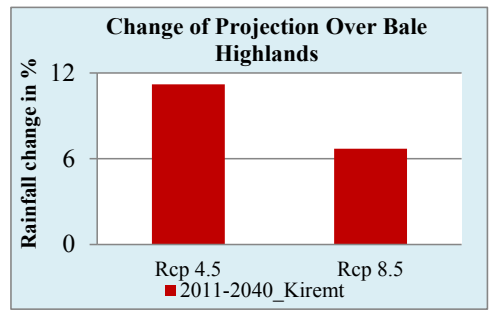

Figure 10d: Change of rainfall at end of near century.

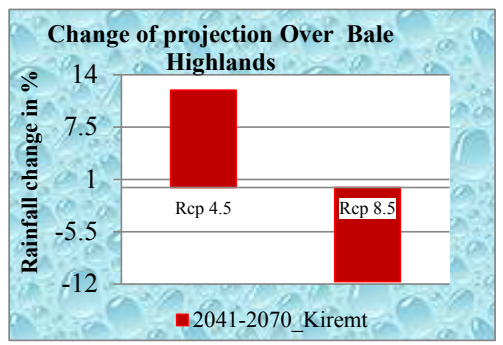

Figure 10e: Change of rainfall at end of mid-century.

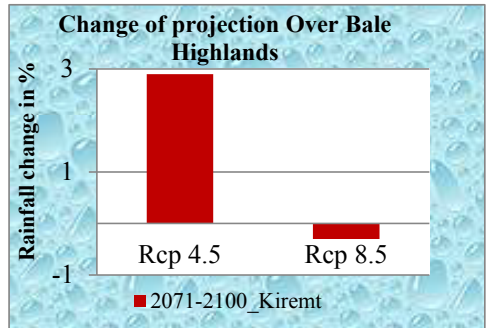

Figure 10f: Change of rainfall at end of century 


\section{Conclusion and Recommendation}

This study was aimed to make in-depth statistical analysis on past and future climatic trend, seasonality of rainfall patterns and climate change linkage to seasonal shifting. It is intended to determine length of growing seasons for various time scales over Bale highlands.

Climate date recorded at meteorological station located in Bale highlands were obtained from NMA Bale Robe Meteorological Branch Directorate while model output of the two emission scenarios were downloaded from CORDEX Africa Group [14]. Various statistical techniques were employed on rainfall and temperature to analyses and interpret the past and future climatic condition and determine onset, cessation and LGP of rainy season over the Bale highlands.

This study was downscale climate change over Bale Highlands by using RCP4.5 and RCP8.5 emission scenarios from CORDEX Africa Data library. The results revealed that the climate change signal was appear over Bale Highlands. The change in temperature over Bale highlands under RCP4.5 and RCP8.5 emission scenarios shown as an increase for the period of near century, mid-century and end century. Changes of temperature under RCP8.5 will higher than the change of temperature in RCP4.5 scenario for all three periods (near, mid and end Century). Rainfall change for near, mid and end centuries under RCPs scenarios were variable. That means ether the change will decrease or increase.

The change of weather parameters like temperature and rainfall over Bale highlands will have both constructive and adverse consequences. If the minimum temperature rises the reproductive of rust will decrease. Similarly, the maximum temperature rises and the rainfall will enhance or reduced it affects social and economic activities over the study areas.

Significantly, understanding the variability of key Belg and Kiremt seasons appearances is crucial for Bale Highlands agricultural planning in general, and especially for mitigating the adverse effects of frequent drought and capitalizing fully when more abundant rains occur. At this point, this study seeks to provide essential climate change information needed in this situation. It is hoped that the availability of this new climate information and its underlying data will encourage improvement of the documentation and analysis of Bale Highland's agricultural management and production, as a further step towards understanding the impacts of climate change in Bale Highlands. Temperature projections from the most recent IPCC report using Representative Concentration Pathways indicate that considerable warming for the region of east Africa [4], this finding also shown as the degree of warming greatest at the end of $21^{\text {st }}$ century in both RCP4.5 and RCP8.5. Sayed [8] has shown that the change in rainfall over the Blue Nile basin would be between +2 and $+11 \%$ for 2030 , while there is also the deficit of rainfall will happen in RCP 8.5 over Bale highlands and access of rainfall will expected in RCP 4.5 at the end of $21^{\text {st }}$ century.

I recommended investigators, this finding shown as the change of rainfall and temperatures in Bale highlands but not accomplish the impact of this change on crop production, water resource etc. so scholars will do further investigation link with climate change impact over Bale Highlands.

\section{References}

1. Hansen JR, Sato RM, Lo K (2006) NASA Goddard Institute for Space Studies and Columbia University Earth Institute, New York, NY, 10025, USA.

2. IPCC (Intergovernmental Panel on Climate Change) (2001) Climate Change 2001. Synthesis report.Cambridge University Press, Cambridge, UK.

3. Conway D, Schipper ELF (2011) Adaptation to climate change in Africa: Challenges and opportunities identified from Ethiopia. Glob Environ Change 21: $227-237$

4. IPCC-Intergovernmental Panel on Climate Change (2014) Climate Change 2014: Impacts, Adaptation, and Vulnerability. Part A: Global and Sectoral Aspects. Contribution of Working Group II to the Fifth Assessment Report of the Intergovernmental Panel on Climate Change Field CB, Barros VR, Dokken KJ, Mach MD, Mastrandrea TE, Chatterjee BM, Ebi KL, et al. (editors), New York, NY, USA, Cambridge University Press, UK.

5. IPCC (Intergovernmental Panel on Climate Change (2007)) Summary for policy makers. Climate change 2007. In: The physical science basis, Working Group contribution to IPCC fourth assessment report: climate change, Geneva.

6. Anyah RO, Qiu W (2012) Characteristic 20th and 21st century precipitation and temperature patterns and changes over the Greater Horn of Africa. Int $J$ Climatol 32: 347-363.

7. Tadege A (editor) (2007) Climate Change National Adaptation Program of Action (NAPA) of Ethiopia. National Meteorological Agency, Addis Ababa, Ethiopia.

8. Sayed MAA (2004) Impacts of climate change on the Nile Flow, Ain Shams University, Cairo, Egypt.

9. Elshamy ME, Seierstad IA, Sorteberg A (2009) Impact of climate change on Blue Nile flows using bias-corrected GCM scenarios. Hydrol Earth Syst Sci 13: $551-565$.

10. FARM Africa and SOS Sahel (2007) Bale Eco-Region Sustainable Management Programme (BERSMP): Annual report.

11. WBISPP (Woody Biomass Inventory and Strategic Planning Project, 1995): Socio-cultural and Economic aspects of crop, livestock and tree production. The Woody Biomass Inventory and Strategic Planning Project.Ministry of Mines and Energy.Ethiopian Energy studies and Research Center.

12. Muleta D, Desalegn O, Bikila Z (2015) Using NDVI for Prediction of Yield for Specific Crop Type: Case Study of Sinana District in Bale Zone.

13. BZFEDO (Bale Zone Finance and Economic Development Office, 2010): Physical and socio Economic profile of Bale zone.

14. http://www.csag.uct.ac.za

15. WMO (2010) Understanding Climate. World Meteorological Organization, Geneva, Switzerland

16. Clarke LE, Edmonds JA, Jacoby HD, Pitcher H, Reilly JM, et al. (2007) Scenarios of Greenhouse Gas Emissions and Atmospheric Concentrations. Sub-report 2.1a of Synthesis and Assessment Product 2.1.Climate Change Science Program and the Subcommittee on Global Change Research, Washington D.C, USA

17. Riahi K, Grübler A, Nakicenovic N (2007) Scenarios of long-term socioeconomic and environmental development under climate stabilization. Techno Forecast Soc Change 74:887-935.

18. Riahi K, Krey V, Rao S, Chirkov V, Fischer G, et al. (2010) RCP-8.5: Exploring the consequence of high emission trajectories. Climatic Change 109: 33-57. 